\title{
Energetic particle monitoring in space: three-decades of experience at IEPSAS
}

\author{
K. Kudela, J. Baláž, I. Strhársky \\ Department of Space Physics, Institute of Experimental Physics, \\ Slovak Academy of Sciences (IEPSAS), \\ Watsonova 47, 04353 Kosice, Slovakia
}

\begin{abstract}
IEPSAS in Košice, Slovakia has a long track of experience with the design, construction, testing and operating of energetic particle detectors at low-altitude and high-apogee satellites as well as interplanetary probes during past 30 years. A review of experiments in space and a brief survey of selected results with references is presented. A simple programmable energetic particle detector MEP-1 developed for COMPASS microsatellite is described with more details. The device can be used for both scientific and application tasks at LEO. In addition to the scientific studies of near Earth environment, the experience obtained can be used in the future also for commercial satellites, where relatively simple, monitoring type of devices for measurement of radiation, especially due to the effects of space weather, are of relevance.
\end{abstract}

\section{IEP SAS IN SPACE EXPERIMENTS}

Along with the cosmic ray ground based observations at Lomnicky Stit, High Tatras mountains by neutron monitor (preliminary data with $1 \mathrm{~min}$ resolution at http://neutronmonitor.ta3.sk), the Department of Space Physics of IEPSAS is studying the dynamics of energetic particle fluxes at energies below those of typical cosmic rays on satellites. The energy range of particles in the environment of Earth from $\sim 10 \mathrm{keV}$ to tens of $\mathrm{MeV}$ is characteristic by large temporal as well as spatial variability of the flux and complexity of physical phenomena in the magnetosphere, near interplanetary space and on the solar surface. Thus relatively simple, monitoring type of instruments of energetic particles have a chance to be utilized in various geophysical/cosmophysical projects. There are four directions of energetic particle research at IEPSAS on satellites, namely (a) dynamics of charged energetic particles at low altitudes, (b) dynamics of particles near the magnetospheric boundaries at high apogee satellites, (c) energetic neutral emissions, and (d) dosimetric measurements with passive detectors on recoverable satellites. Table I presents a list of names of instruments on satellites with participation of IEPSAS in the past. The passive measurements (9 experiments on Cosmos and MIR station) are not included in the list. In the list there are two projects (COMPASS and CESAR) for which the devices were constructed at IEPSAS, but the future of the projects is not clear.

Table I.

Review of space projects with participation of Institute of Experimental Physics (electronical devices)

\begin{tabular}{|c|c|c|c|c|c|}
\hline $\begin{array}{l}\text { Device } \\
\text { name }\end{array}$ & $\begin{array}{l}\text { Space } \\
\text { Project }\end{array}$ & $\begin{array}{l}\text { Launch } \\
\text { Date }\end{array}$ & $\begin{array}{l}\text { Per. } \\
{[\mathrm{km}]}\end{array}$ & $\begin{array}{l}\text { Apogee } \\
{[\mathrm{km}]}\end{array}$ & $\begin{array}{l}\mathbf{i} \\
{\left[{ }^{\circ}\right]}\end{array}$ \\
\hline PG-1 & IK-3 & 7.8.1970 & 206 & 1315 & 48,4 \\
\hline PG-1A & IK-5 & 2.12.1971 & 196 & 1202 & 48,6 \\
\hline PG-1B & $I K-13$ & 27.1 .1975 & 278 & 1681 & 83,5 \\
\hline SK-1 & IK-17 & 24.9.1977 & 466 & 511 & 83 \\
\hline DOK-T & PROGNOZ-8 & 20.9.1981 & 980 & 197390 & 65 \\
\hline URE-1 & VERTICAL-10 & 21.12 .1981 & 0 & 1510 & - \\
\hline DOK-1 & INTERSHOCK & 26.4 .1985 & 421 & 200520 & 65 \\
\hline SPE-1 & ACTIVE & 28.9 .1989 & 511 & 2487 & 82,6 \\
\hline DOK-S /1 & ACTIVE & 28.9 .1989 & 511 & 2487 & 82,6 \\
\hline DOK-S /2 & APEX & 18.12 .1991 & 440 & 3050 & 82,5 \\
\hline SONG-E & CORONAS-I & 2.3 .1994 & 500 & 500 & 83 \\
\hline DOK-2X & INTERBALL-X & 3.8 .1995 & 371 & 193000 & 65 \\
\hline DOK-S /3 & INTERBALL-X & 3.8 .1995 & 371 & 193000 & 65 \\
\hline DOK-2A & INTERBALL-A & 29.8 .1996 & 7144 & 25502 & 62,8 \\
\hline DOK-S /4 & INTERBALL-A & 29.8 .1996 & 7144 & 25502 & 62,8 \\
\hline SPE-1M & SPE-MIR & 1996 & 324 & 352 & 51,6 \\
\hline SLED-2 & MARS-96 & 16.11 .1996 & 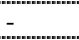 & - & - \\
\hline SPRUT-6 & SPRUT & Oct. 1998 & 324 & 352 & 51,6 \\
\hline SONG-M & CORONAS-F & 30.7 .2001 & 500 & 500 & 83 \\
\hline EPD & CESAR & ? & 400 & 1000 & 70 \\
\hline MEP-1 & COMPASS & ? & 350 & 400 & 79 \\
\hline
\end{tabular}

\section{Charged Energetic Particles at Low Altitudes}

\section{Earlier activities. SPE-1 on Active}

Study of energetic charged particle fluxes at IEP SAS at low altitudes started from data analysis of the device PG1 on IK-3 and continued at IK-5 and IK-13 (Table I). These instruments were developed in other laboratories of former Czechoslovakia. The main tasks were study of the sources, losses and mechanisms of transport of trapped particles in the magnetosphere. After 1975 the design and construction of instruments for low altitude measurements of energetic particles started in Kosice. The first experiment devoted to magnetospheric charged particle dynamics constructed in cooperation of IEPSAS and Technical University of Kosice was URE-1, using the detectors at scanning platform for the measurements 
of angular distribution of electrons and ions at middle latitudes up to $1510 \mathrm{~km} \mathrm{[1].}$

On the satellite Active (IK-24) the instrument SPE-1 (Spectrometer of Protons and Electrons) constructed at IEPSAS in cooperation with Space Research Institute in Moscow (SRI) was placed. Three pairs of silicon detectors in different orientations with respect to the zenith axis of the satellite were used. In each pair, one detector for electrons covered by a Mylar foil stopping protons up to $\sim 700 \mathrm{keV}$ and another one with magnetic filter rejecting electrons up to $\sim 650 \mathrm{keV}$ were used. The active cooling with the help of Peltier elements was used to reduce the noise and to allow putting energy threshold to relatively low values. Energy spectra of protons $\sim 25-$ $800 \mathrm{keV}$ and electrons $\sim 20-400 \mathrm{keV}$ were measured in various modes. Relatively large amount of measurements from September 1989 until May 1992 from the main telemetry system as well as from direct transmissions of data is available [2]. Using the mode with 32 energy channels the inner zone multiple peaks in energy spectra with the lowest one at $\sim 30 \mathrm{keV}$ were found in the trapped population at $\mathrm{L}<1.30$ at altitudes above $800 \mathrm{~km}$. The long drift period of such electrons indicated that the drift acceleration resonance model proposed to explain peaks at higher energies is inappropriate for those measurements [3]. Using the excentric orbit of Active, SPE-1 measurements combined with those at MIR station were used to describe the occurrence of short time spikes of energetic protons near equator at very low $\mathrm{L}$ values (where the stable trapping is not possible) on altitude, local time and geomagnetic activity [9].

High temporal resolution allowed with using SPE-1 to observe the high frequency energetic electron $(\sim 20$ to $\sim 300 \mathrm{keV}$ ) pulsations in middle latitudes, in subauroral and auroral regions and to identify differences at different pitch angles close to the equatorial loss cone. While strong, short time and/or small scale size pulsations of energetic electrons in different energy ranges in $20-300 \mathrm{keV}$ within the loss cone have been observed during the recovery phase of a substorm in the morningside auroral and subauroral regions, simultaneous measurements outside the local loss cone did not exhibit such structure [4]. The dependence of durations of the spikes on $\mathrm{L}$ as well as relations to VLF emissions were found.

Data obtained from SPE-1 were also used for a case study of particle intensity variations around the time of an earthquake. Sudden increases of energetic electron fluxes were observed over the Asian zone near the epicenter of the Iranian earthquake in June 1990 [5].

\section{MEP-1 instrument.}

Based on the experience from SPE-1 and other low altitude experiments, the Monitor of Energetic Particles (MEP-1) was recently designed and constructed at
IEPSAS in collaboration with institutes in abroad for the low altitude COMPASS project (LEO, $\left.350 \mathrm{~km} \times 79^{\circ}\right)$. The scientific objectives of MEP-1 for that project were defined as (a) checking the relevancy of low altitude energetic particle observations for eventual seismic forecasting purposes, (b) updating the models of particle fluxes within and beneath the regions of stable trapping, (c) features of energy spectra of ions and electrons in the South Atlantic magnetic anomaly, and (d) fine structure of particle bursts near and within the local loss cone [8]. The device is described with more technical details in papers $[6,7,21]$. The design and construction can be used at LEO for both the scientific tasks mentioned above as well as for monitoring of radiation at commercial spacecrafts. MEP-1 is a simple energetic particle detecting device designed with capability of transparent performance reconfiguration as may be required by experimenter during the active operation on the orbit.

Basic parameters of the MEP-1 instrument are as follows:

Weight/ Dimensions ............ 2.1kg / 210 $\times 160 \times 150 \mathrm{~mm}$

Power consumption: .................. 0.7 W @ $28 \mathrm{~V}$

Field of view / geom. factor........ 30 $/ 0.03 \mathrm{~cm}^{2}$.ster

Energy range - ions ................ 15keV - 3.2 MeV

Energy range - electrons .......... 15keV - $350 \mathrm{keV}$

Number of energetic channels: ...1-32 (programmable)

Electrical thresholds ................ programmable in range

$15-1270 \mathrm{keV}$, step $5 \mathrm{keV}$

Time resolution: $31.25 \mathrm{~ms}$ (32 samples / s)

The MEP-1 comprises a detection system equipped with four solid state detectors (PIPS) that are organized in two mutually perpendicular pairs. Each pair of detectors consist of an ion detector (equipped with broom magnet) and of an electron detector (equipped with mylar foil).

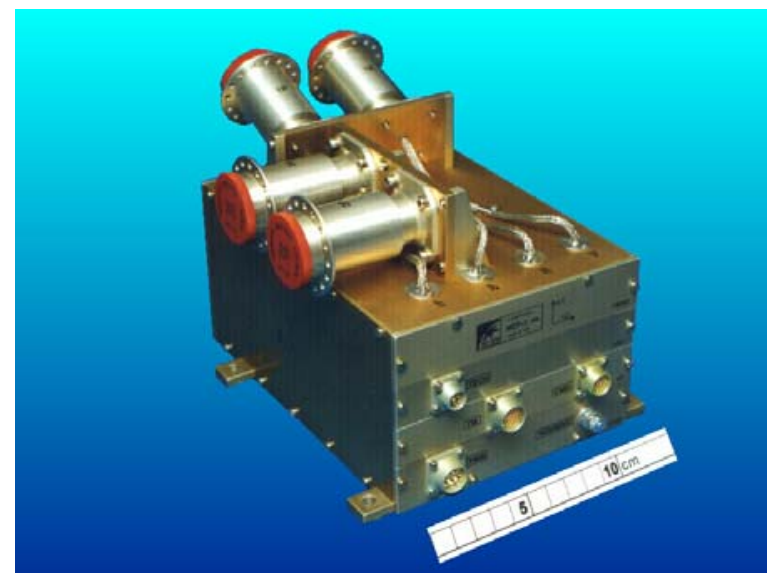

Fig.1. The MEP-1 instrument. 


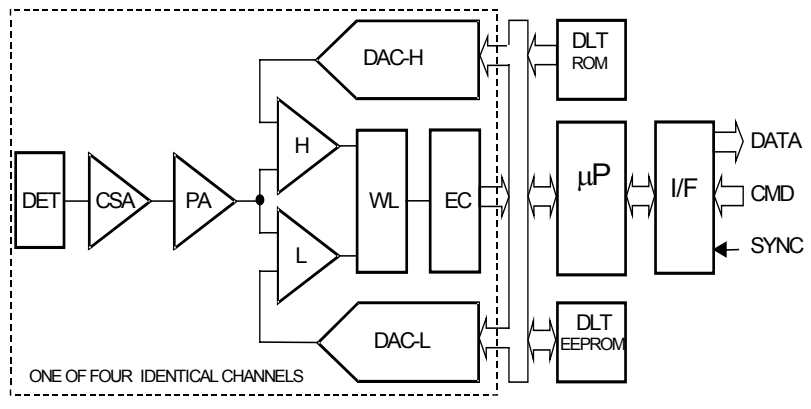

Fig. 2. Functional block diagram of MEP-1

The processing electronics is based on single-channel window discriminators where both discrimination levels are under flexible software control from the microprocessor with a pair of DACs. If the particle energy complies with the current energetic window, a pulse is generated by a precise window logic (WL) circuitry that is then recorded by an event counter (EC). The gatig, reset and readout of the counter is performed by the microprocessor. The basic telemetry data acquisition period ( 1 second) is divided to 32 registration periods, so that the sampling rate is $32 \mathrm{~Hz}$. The discrimination thresholds of the window discriminators are set individually for each registration period. The full set of discrimination levels for whole telemetry acquisition period is defined by a discrimination level table (DLT) that is allocated in the operation memory of the instrument. MEP-1 allows to define 255 individual DLTs, each of them can be activated by a telecommand. While 128 DLTs are preprogrammed in the PROM memory already during instrument development and calibration, another 127 DLTs are alocated in the EEPROM memory and can be programmed also during the flight on the orbit. Thus the experimenter can define and run new instrument operational modes and so that provide a "focusing" to the relevant physical phenomenon with regard to current data analysis.

\section{ENERgetic Particles at High ApogEe SATEllites}

The energy range from few $\mathrm{keV}$ to few $\mathrm{MeV}$ is of interest in space physics in particular because it reveals to a great extent the effects of interplanetary travelling shocks and planetary shock waves and the processes of energy exchange between waves and particles in the palnetary magnetospheres. Also, the acceleration processes in the magnetospheric tail can be studied within this energy range. One of the problems is in the coverage of wide energy range from plasma energies to $\mathrm{MeV}$. At low energies the deflection in electric and magnetic fields are used over long time. These methods however do not provide sufficient large geometrical factors above $\sim 10 \mathrm{keV}$. On the other hand, semiconductor detectors used at higher energies have usually relatively high noise and their low energy threshold is not overlapping with plasma spectrometers.
One of the possibilities to decrease the noise level is cooling the detector plus preamplifier system. While the active cooling was used at SPE-1 at low altitudes, the passive cooling, utilizing the natural shadow of the satellites of Prognoz-type was used for high apogee measurements in cooperation with SRI Moscow and other laboratories in abroad. The passive cooling allowed to measure particles above $\sim 15 \mathrm{keV}$ in DOK-T experiment on Prognoz-8 [10,11]. DOK-T device on Prognoz 8 confirmed the possibility of passive cooling and allowed to observe bidirectional fluxes of ions within the magnetosheath [12].

An improved version of DOK-T was constructed at IEPSAS in collaboration with SRA Moscow and Astronomical Institute in Prague for Intershock project (DOK-1 [13]). Three pairs of silicon detectors at different angles with respect to the spin axis of the satellite were used. A magnetic filter to ensure the electron deflection without affecting protons was put in front of one of detectors (proton). Several characteristics of the energetic particles in the vicinity of bow shock and magnetopause were obtained from those measurements, e.g. [14-16].

For the Interball project the two energetic particle instruments for the pair of main satellites (DOK-2) and for the two subsattelites Magion 4 and 5 constructed in Prague (DOK-S) were designed and developed at IEPSAS in collaboration with SRI Moscow and Demokritos U. of Thrace, Greece. The main scientific tasks and devices are described in [17-20].

Long time data sets obtained from the DOK-2 instruments on Interball satellites and DOK-S instruments on Magion 4 and 5 lead to the extensive statistical and detailed case studies of the characteristics of energetic ion and electron flux in the magnetosheath, in the vicinity of the bow shock, in near interplanetary space and in the geomagnetic tail, e.g. [22-25].

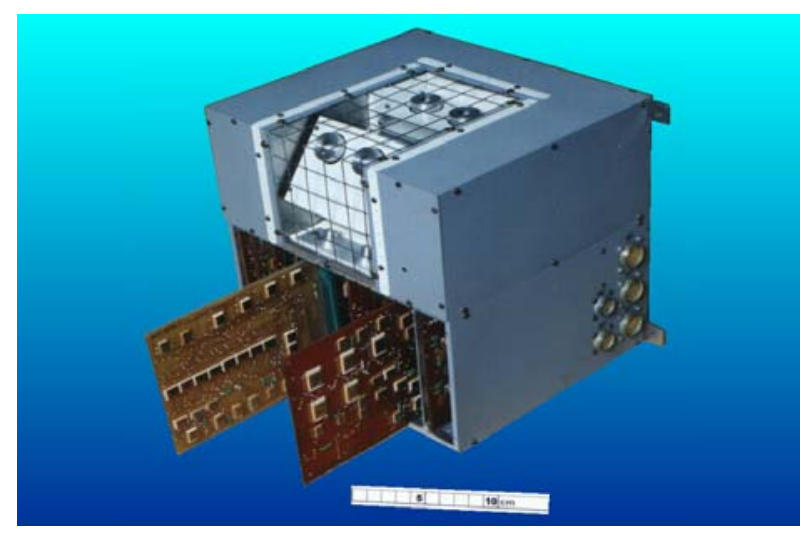

Fig. 3. DOK-2 instrument provided > 5 years of measurements of ions and electrons on Interball- 1 and $>2$ years of measurements on Interball-2 satellites.

The detailed energy spectra (56 energy channels for ions and electrons) allowed to observe dispersive velocity events in the outer magnetosphere. According to them the time and position of instantaneous particle injection 
on the nightside magnetosphere can be observed by DOK-2 remotely. Their occurrence on Interball-2 orbit is summarized in [26].
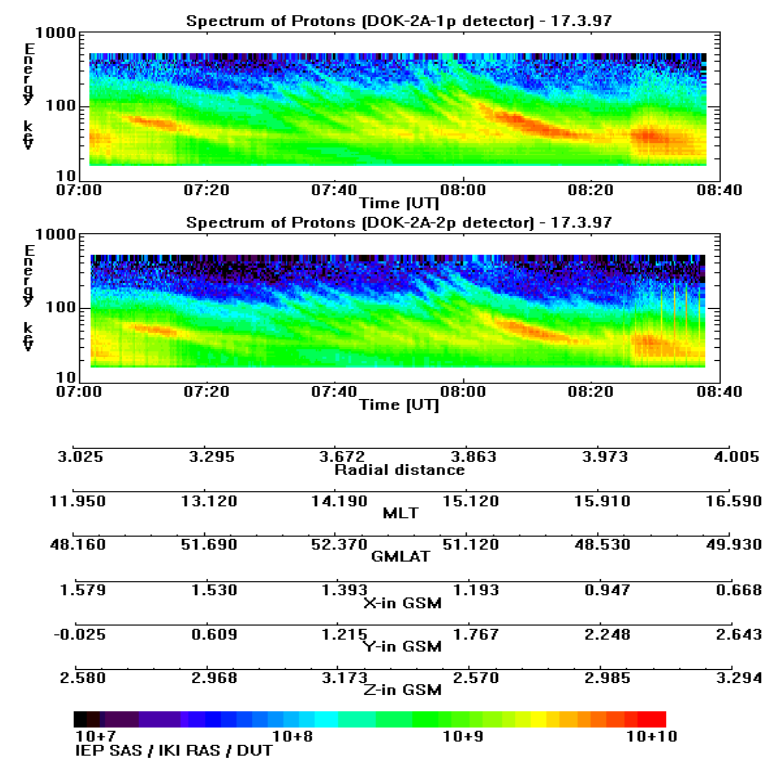

detectors of DOK-2 on Interball-2 in the dayside outer magnetosphere.

\section{ENERGETIC NEUTRAL EMISSIONS}

The first experiments devoted to the detection of possible solar neutron responses above the surface of the Earth with participation of IEP SAS were done on balloons in the former Soviet Union, in the cooperation with FTI Leningrad. The detector system BANAN [27] was used in two balloon flights in 1975-1976. The neutron sensor (He3 counter) was surrounded by a plastic scintillator for the detection of recoil protons and both were surrounded by the ring of Geiger counters used as the anticoincidence guard for the charged particles.

The experience from the technological experiment BANAN was used in its improved version, namely in detector system SK1 [30], which was developed for the satellite IK-17. The plastic scintillator serving for detection of recoil protons was replaced by the liquid one (NE-213) and the anticoincidence guard was constructed from the plastic scintillator. In both experiments the pulse shape discrimination separating the responses from neutrons and gamma rays [28,29] was used. IK-17 satellite was launched in Russia in September 1977 on the circular orbit $\sim 500 \mathrm{~km}$ with the inclination $\sim 83^{\circ}$. SK1 was devoted to the detection of neutrons $1-30 \mathrm{MeV}$ and gammas $0.15-6 \mathrm{MeV}$. It was placed on a stick $1 \mathrm{~m}$ out from the satellite body to decrease the albedo of the satellite body. The study oriented to albedo neutrons and gamma rays provided useful information on the background which must be assumed in satellite measurements of solar neutrons. Relatively precise differential intensity of neutron albedo flux at the invariant latitude $42.7^{\circ}$ and solar minimum was obtained for the energy interval $1-30 \mathrm{MeV}$ [31]. The results were compared with the computational results, with balloon measurements and with the satellite measurement covering at that time energy $<10 \mathrm{MeV}$. Also latitudinal profile of albedo neutrons and gamma rays at $500 \mathrm{~km}$ was obtained from that measurement [32].

CORONAS-I satellite was launched in Russia in March 1994 on circular orbit $\sim 500 \mathrm{~km}, 83^{\circ}$ inclination. The set of experiments was devoted to study of various aspects of solar activity. Electromagnetic and corpuscular emissions from the Sun have been observed. One of devices is SONG [33], a joint experiment of Moscow State University and IEPSAS. The detector is CsI(Tl) crystal with anticoincidence shielding. Gamma rays 0.1$100 \mathrm{MeV}$, neutrons 1-60 MeV and electrons 11-108 MeV have been detected by the device. The nominal orientation was towards the Sun. The detailed maps of flux of gamma rays in different energies were obtained and the two components, namely (1) that due to interactions of primary cosmic rays with residual atmosphere and (2) due to bremsstrahlung by high energy magnetospheric electrons, were identified.

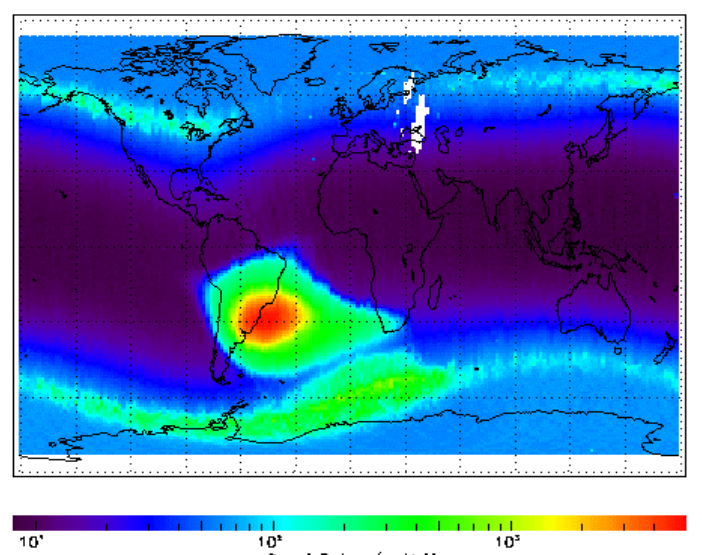

rig. ग. Vetallea map OI $3-8.3$ IMe $500 \mathrm{~km}[34]$.

Gamma and hard $\mathrm{X}$ ray from the Sun was measured earlier on satellites e.g. OSO-7, SMM, CGRO, YOHKOH, GAMMA, GRANAT and others. At present hard electromagnetic spectral range is observed on satellites by RHESSI and by CORONAS-F.

The CORONAS-F satellite (scientific leader V. N. Oraevsky) was launched on July 31, 2001, Russia, into low altitude nearly polar orbit. It is oriented towards the Sun. One of the instruments, devoted to charged energetic particles and high energy neutral emission measurements from the Sun, is complex SKL (or SCR, Solar Cosmic Rays) coordinated by Moscow State University (S.N. Kuznetsov is PI). One instrument within the complex is SONG-M, an improved version of SONG on CORONAS-I. IEPSAS participates in SONG-M development and data analysis. The instrument, working from August 2001 until present, is capable to observe hard $\mathrm{X}$ and gamma rays of solar origin when it is outside the radiation belts or not shadowed by Earth. Background of $\mathrm{X}, \gamma$ and neutrons is changing along the satellite orbit. A uniquely strong emission of solar gamma rays up to 
very high energy was observed on August 25, 2001 [35]. During that flare SONG-M detected enhancements in neutron channels after main gamma peak. The event was identified (among the available measurements by SONGM until June 2003) as the event with the highest energy emission of gamma, and a clear signal in neutron channels was detected in coincidence with the ground based observations by a neutron monitor [36].

Recently, IEPSAS is participating on the project NUADU (energetic neutral atom imager) for European Chinese Double Star mission (S. McKenna-Lawlor is PI, short description in [37]).

Acknowledgement.

The design, development, testing and construction of many instruments mentioned above was done by other colleagues of IEP SAS and TU Kosice. The authors wish to acknowledge them, especially to J. Rojko, L. Michaeli and P. Opatrny. The cooperation with several institutes in abroad, especially with Moscow University, RSI, FTI Leningrad, DUT Greece is acknowledged. The APVT grant agency, project 0259, is acknowledged for support.

\section{REFERENCES}

[1] P.V. Vakulov, T.I. Pervaya, B.Y. Tscherbovsky, I. Kimak, K. Kudela, P. Opatrny, Proton and electron streams on the atmosphere vertical probe Vertical-10, Geomagn. Aeron., 24 (6), 1002, 1984

[2] K. Kudela, M. Slivka, Energetic particle data archived at IEPSAS, in Radiation Belts: Models and Standards, AGU Geophysical Monograph 97, ed. J.F. Lemaire, D. Heynderickx, D.N. Baker, 259-264, 1996

[3] K. Kudela, J. Matisin, F.K. Shuiskaya, O.S. Akentieva, T.V. Romantsova, D. Venkatesan, Inner zone electron peaks observed by the ACTIVE satellite, J. Geophys. Res., 97, A6, 8681-8683, 1992

[4] K. Kudela, I.M. Martin, F.K. Shuiskaya, M.M. Mogilevsky, F. Jiricek, Pulsations of precipitating energetic electrons: ACTIVE satellite data, J. Atmos. Solar Terr. Physics, 60, 643-653, 1998

[5] J. Bošková, J. Šmilauer, P. Tř́iska, K. Kudela, Anomalous behaviour of plasma parameters as observed by the IK-24 satellite prior to the Iranian earthquake of June 20, 1990, Studia geophysica et geodaetica, 38, 213220, 1994

[6] J. Baláž, V.A. Gladyshev, K. Kudela, I.M: Martin, I. Strhársky, Programmable spectrometer of energetic particles for space research, Instruments and Experimental Techniques, 41, 710-713, 1998

[7] J. Baláž: Design and system identification of energetic particle spectrometers to be flown on board a spacecraft. Doctoral thesis. Technical University Kosice,
Faculty of Electrical Engineering and Computer Science. Kosice 1998

[8] K. Kudela, J. Baláž, I. Strhársky, J. Štetiarová, I.M. Martin, V.A. Gladyshev, F.K. Shuiskaya, A. Stepanov, V. Klepikov, MEP-1 Experiment: Scientific Tasks and Basic Characteristics, preprint UEF-02-97, Kosice, pp. 23, 1997

[9] E. Grachev, O. Grigoryan, J. Juchniewicz, S. Klimov, K. Kudela, A. Petrov, J. Stetiarova, Low energy protons on $\mathrm{L}<1.15$ in $500-1500 \mathrm{~km}$ range, Adv. Space Res., 30, 1841-1845, 2002

[10] S. Fischer, K. Kudela, V. Lutsenko, J. Rojko, Measurements of energetic particles by DOK-T Instrument, in "Intershock Project", Pub. Of the Astronomical Inst. Czechoslovak Acad. Sci., No 60, 73$84,1985 a$

[11] J. Rojko, V.Lutsenko, Instrument to study of charged particles using passive cooling of semiconductor detectors, Report at the Symposium "Scientific Instruments for Space Research “, Odessa, 1982

[12] K. Kudela, V. Lutsenko, N. Pissarenko, J. Rojko, S. Fischer, Pitch angle distribution of protons (Ep>12 keV) in low altitude transition region, Space Res. (in Russian), 23, No 2, 317-321, 1985

[13] S. Fischer, K. Kudela, V. Lutsenko, J. Matisin, J. Rojko, DOK-1 Instrument, in "Intershock Project", Pub. Of the Astronomical Inst. Czechoslovak Acad. Sci., No 60, 166-167, 1985

[14] K. Kudela, D.G. Sibeck, R.D. Belian, S. Fischer, V. Lutsenko, Possible leakage of energetic charged particles from the magnetosphere into the upstream region on June 7, 1985, J. Geophys. Res., 95, 20825-20832, 1990

[15] K. Kudela, D.G. Sibeck, M. Slivka, S. Fischer, V. Lutsenko, D. Venkatesan, Energetic electrons and ions in the magnetosheath at low and medium latitudes Prognoz 10 data, J. Geophys. Res., 97, A10, 1484914857, 1992

[16] K. Kudela, D.G. Sibeck, M. Slivka, Prognoz-10 energetic particle data - leakage from the magnetosphere versus bow shock acceleration, J. Geophys. Res., 99, A12, 23461-23472, 1994

[17] S. Fischer, K. Kudela, Energetic particles in the magnetospheric tail, in "Plasma processes in Magnetosphere of Earth", in Russian, Proceedings of the seminar, Plovdiv, Bulgaria, p. 110-127, 1982

[18] V. Lutsenko, J. Rojko, K. Kudela, T.V. Gretchko, J. Baláž, J. Matišin, E.T. Sarris, K. Kalaitzides, N. Paschalidis, Energetic particle experiment DOK-2 
(INTERBALL project), in ,Interball mission and payload", CNES, RSI, 249-255, 1995

[19] K. Kudela, M. Slivka, J. Rojko, V. Lutsenko, The apparatus DOK-2 (Project INTERBALL): output data structure and modes of operation, preprint IEPSAS, UEF-01-95, Kosice, pp. 37, 1995

[20] K. Kudela, J. Rojko, J. Matišin, J. Baláž, I. Strhársky, L. Michaeli, P. Opatrný, E.T. Sarris, K. Kalaitzides, DOK-S, Project Interball, Payload description and documentation, preprint IEPSAS Košice, UEF-01-96, pp. 69, 1996

[21] J. Baláž, I. Strhársky, Programmable particle spectrometer MEP-1 and dedicated ground support equipment. Technical Description and user's guide, preprint, pp. 48, Košice, 1996

[22] V.N. Lutsenko, V.N., K. Kudela, Almost monoenergetic ions near the Earth's magnetosphere boundaries, Geophys. Res. Lett., 26, No 3, 413-416, 1999

[23] K. Kudela, K., V.N. Lutsenko, D.G. Sibeck, and M. Slivka, Energetic ions upstream of the Earth's bow shock: Interball-1 survey, Adv. Space Res., 30, No 12, 2731-2736, 2002

[24] S.-W. Chang, J.D. Scudder, K. Kudela, H.E. Spence, J.F. Fennell, R.P. Lepping, R.P. Lin, and C.T. Russell, $\mathrm{MeV}$ magnetosheath ions energized at the bow shock, $J$. Geophys. Res., 106, p. 19,101-19,115, 2001

[25] S. McKenna-Lawlor, K. Kudela, K. Kecskemety, S.W. Chang, Spacecraft measurements of ions and electrons (> $40 \mathrm{keV})$ near and far upstream of the Earth's bow shock, Adv. Space Res., 31 (4), 933-938, 2003

[26] K. Kudela, V.N. Lutsenko, D.G. Sibeck, M. Slivka, T.V. Gretchko, E.T. Sarris, High energy particle dispersion events observed by Interball-1 and-2, Adv. Space Res., 30 (12), 2849-2854, 2002

[27] J. Dubinský, J., K. Kudela, Yu. E. Efimov, Yu. A. Chichikalyuk, L. Michaeli, T. Vašek, Apparatus for balloon measurements of the neutron flux, Bull. Astron. Inst. Czech., 28, 241, 1977

[28] L. Michaeli, in Scientific space instrumentation (in Russian), Moscow, Metalurgia, 119, 1983

[29] A.A. Gusev, M.I. Panasyuk, G.I. Pugacheva, L. Michaeli, and J. Saliga, Izv. Moscow University, ser. 3, Physics and Astronomy, 30, No 6, p. 126, 1989

[30] Yu.E. Efimov, K. Kudela, L. Michaeli, J. Rojko, Yu. A. Chichikalyuk, in Scientific space instrumentation (in Russian), Moscow, Metalurgia, 76, 1983
[31] J. Dubinsky, Yu.E. Efimov, K. Kudela, L. Michaeli, J. Rojko, Yu.A. Chichikalyuk, Study of neutrons of Earth's albedo on satellite IK-17, Izv. AN, ser. Fiz., 46, No 9, 1680-1682, 1982

[32] Yu.E. Efimov, A.A. Gusev, K. Kudela, L. Just, G.I. Pugacheva, Spatial distribution of albedo particles on altitudes $\sim 500 \mathrm{~km}$, Czech. J. Phys., B35, 1371-1381, 1985

[33] J. Balaz, A.V. Dmitriev, M.A. Kovalevskaya, K. Kudela, S.N. Kuznetsov, I.N. Myagkova, Yu.I. Nagornikh, J. Rojko, S.P. Ryumin, Solar flare energetic neutral emission measurements in the project CORONAS-I, in IAU Colloq. 144, Bratislava, VEDA, 635-640, 1994

[34] R. Bučík, K. Kudela, A.V. Bogomolov, I.N. Myagkova, S.N. Kuznetsov, S.P. Ryumin, Distribution of gamma ray fluxes at altitude $500 \mathrm{~km}$ : Coronas-I data, Acta Phys. Slovaca, 50 (2), 267-274, 2000

[35] S.N. Kuznetsov, K. Kudela, I.N. Myagkova, B.Yu. Yushkov, Gamma and X-ray solar flare emissions: CORONAS-F measurements, Proc. $28^{\text {th }}$ ICRC, Tsukuba, Japan, 6, 3183-3186, 2003

[36] Y. Watanabe, Y. Muraki, K. Murakami, T. Sako et al, Solar neutron event in association with a large solar flare on August 25, 2001, Proc. 28 ${ }^{\text {th }}$ ICRC, Tsukuba, Japan, 6, 3179-3182, 2003

[37] S. McKenna, J. Baláž et al, A neutral atom detector (NUADU) for the Chinese Double Star Polar Mission, Book of abstracts „Magnetospheric Response to Solar Activity“, Charles U. Prague, p. 34, Prague, Sept. 2003 